\title{
Experimental and numerical analysis of epoxy based adhesive failure on mono- and bi-material single lap joints under different displacement rates
}

\author{
Hojjat Ghahramanzadeh Asl \\ Karadeniz Technical University, Turkey \\ b.kahramanzade@ktu.edu.tr, bttp://orcid.org/0000-0002-9078-1933 \\ Salim Çam, Osman Orhan, Adnan Özel \\ Erzincan Binali Yaldorm University, Turkey \\ scam@erzincan.edu.tr, bttp://orcid.org/0000-0003-2603-8691 \\ osman.orban@erzincan.edu.tr, bttp:/ / orcid.org/0000-0002-1632-0207 \\ adnanozel@erivincan.edu.tr, bttp:/ / orcid.org/0000-0001-8527-3136
}

\begin{abstract}
Development in material science imposes to use different materials in production. This causes a problem for joining different materials because traditional joining techniques such as welding could not overcome this problem in industries such as automotive. Hence, adhesive bonding overcomes this problem by its superiorities to join different materials. The joint strength of epoxy-based adhesives is affected by adhesive thickness, adherent's surface quality, and curing conditions. In this study, two different materials (SAE 304 and AL7075) were bonded by epoxy adhesive (3M DP460NS) as single lap joint (SLJ) of Aluminum-Aluminum, Steel-Steel, and Aluminum-Steel. The effects of adhesive thickness $(0.05,0.13,0.25 \mathrm{~mm})$ and surface roughness $(281,193,81 \mathrm{~nm})$ to strength were compared. SLJs were tested for 1, 10, 25 and $50 \mathrm{~mm} / \mathrm{min}$ displacement rates. Adhesive surface structures were imaged by Scanning Electron Microscopy (SEM) to investigate adhesive fractures. Surface roughnesses were examined by using Atomic Force Microscopy (AFM) to compare its influence on failure load. Finite Element Analysis (FEA) was conducted by using Cohesive Zone Model with ANSYS 18.0 software to obtain stress distribution of adhesive.

Optimum values according to the present conditions of the thickness $(0.13 \mathrm{~mm})$ and roughness $(<200 \mathrm{~nm})$ were determined. Experimental results were demonstrated that while displacement rates rose, failure loads increased as well. FEA analysis was fit to experimental results. It has been observed that along with material type, peel stresses become an important factor for joint strength.
\end{abstract}

KEYWORDS. Single lap joint, Epoxy adhesive, Displacement rate, Thickness, Surface roughness.

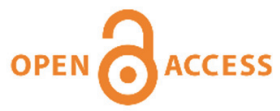

Citation: Kahramanzade, H., Çam, S., Orhan, O., Özel, A., Experimental and Numerical Analysis of Epoxy Based Adhesive Failure on Mono- and Bi-Material Single Lap Joints Under Different Displacement Rates, Frattura ed Integrità Strutturale, 52 (2020) 9-24.

Received: 07.11.2019

Accepted: 13.12 .2019

Published: 01.04.2020

Copyright: (C) 2020 This is an open access article under the terms of the CC-BY 4.0, which permits unrestricted use, distribution, and reproduction in any medium, provided the original author and source are credited. 


\section{INTRODUCTION}

A erospace, naval and automotive industries have been using composite materials along with steel and aluminum for structure lately. Due to the difficulties of joining of two or more different materials, adhesive joints become more suitable in the application. While joining technique should enable the ability to bond different materials, it also should be strong enough regarding strength. Although the performance of the joint under static and dynamic conditions is essential, crashworthiness of joint is also considered as crucial in case of accidents. As for crashworthiness, it highly depends on the strain rate of impact [1,2]. Single lap joint (SLJ) is widely used for adhesive joints due to its easy application, simple geometry and explicit results in order to understand joint strain rate dependency [3].

There are some inconsistent factors that affect adhesive SLJs strength. For instance, a structural adhesive DP460, manufactured by $3 \mathrm{M}$, technic sheet suggests aluminum adherend's overlap shear strength as around $30 \mathrm{MPa}$ when epoxy fully cured. Some researchers report that it could be $13.6 \mathrm{MPa}$ curing conditions at $140^{\circ} \mathrm{C}$ for $60 \mathrm{~min}$ [4], $23.6 \mathrm{MPa}$ at 60 ${ }^{\circ} \mathrm{C}$ for $120 \mathrm{~min}$ [5] and $13.9 \mathrm{MPa} 23^{\circ} \mathrm{C}$ for 2 days [6]. Along with this, adhesive strength enhancement studies have been proposed by others $[7,8]$ and these pure adhesive strengths were used as a reference of base adhesive strength. These studies focused on strain rate, adhesive thickness or surface quality of adhesive joints but few of them considered all of these together in one work. However, these parameters are interconnected between and impose bond strength crucially $[9,10]$. Although some of the studies report different adhesive strengths with high fluctuation $[5,11-13]$ experiments need to be performed by considering all factors into account to clarify results.

From this perspective of view, separate works have been conducted by researchers by taking thickness, overlap length, adherend type, adherend thickness, strain rate, and surface quality into consideration. Bamberg et al. [6] conducted SLJ tests by changing adhesive thickness, overlap length and adherents using DP460 (3M) adhesive. They concluded that increasing overlap length from 7 to 25 improved failure load of joints. Aydin et al.[11] compared different adherend thicknesses and overlap lengths by using the same adhesive at $0.28 \mathrm{MPa}$ curing pressure and $0.12 \mathrm{~mm}$ adhesive thickness. They reported that increasing adherend thickness also distributed stress concentrations from edges to the middle of the adhesive layer. They have not supplied the effects of different curing pressure and adhesive thickness while other factors change. By using the same adhesive, similar thickness and aluminum adherents; failure load of SLJ was reported by Bamberg et al. [6] as 8.7 $\mathrm{kN}$ and Gültekin et al.[8] as $14.7 \mathrm{kN}$. This difference of $68 \%$ needs to be explained by further studies.

Adams and Peppiatt[14] investigated the effects of adhesive thickness on failure load by adopting five approaches then predicted an intersection point at $0.13 \mathrm{~mm}$ as an ideal adhesive thickness. Niranjan[15] reported three independent factors that were affected by adhesive thickness; adhesive defects, stresses, and strain rate. Adams and Peppiatt landed up the presence of voids and microcracks in the adhesive layer that affects adhesive strength which was the first consideration of Niranjan. Further study by Grant et al. [16] concluded that while adhesive thickness increased, the bending moment also amplified. This caused a decrease of joint strength which is related to Niranjan's second consideration. Although this adhesive thickness is widely accepted as optimum adhesive thickness for SLJ, it needs to be investigated more due to the reliance of stress on the single lap joint, its dependence of strain rate and adherend material. Along with previous studies, a study that considers both the effects of overlap length and strain rate under impact and quasi-static conditions conducted by Araújo et al. [17]. They concluded that $25 \mathrm{~mm}$ overlap length provides better damping than 12.5 and $50 \mathrm{~mm}$ overlap lengths.

Blackman et al.'s study [18] showed crack propagation with regards to the test rate for adhesively bonded joints. According to their results, while the test rate increased, crack formation velocity accelerated, thus adhesive fracture energy lowered. Lißner et al. [19] investigated the rate dependency of adhesive joints. They used 3 different surface treatments, adhesive thicknesses and loading rates for this purpose. They concluded that for higher loading rates; while stress in adhesive increased, the energy that disappears during fracture decreased independently of adhesive thickness. When adhesive thickness set from 0.3 to 1.0, stress in joints tended to reduce. Trimino et al. [12] employed epoxy adhesives (include 3M DP460NS) to determine strain rate dependency. They applied quasi-static and impact tests on the adhesive samples. They found that stress at failure augmented by increasing the strain rate. Avendaño et al. [20] conducted tests on SLJ's under two crosshead speeds. They observed that while speed rose from $1 \mathrm{~mm} / \mathrm{min}$ to $100 \mathrm{~mm} / \mathrm{min}$, failure loads amplified by $14 \%$. Boutar et al. [21] investigated the effect of surface roughness on adhesive joint failure. They used sandpaper from 50- to 1000-grid afterward measured surface roughnesses of adherends. They reported that surface roughness decreased by using fine-grained sandpaper consequently bond strength of joint improved.

Among approaches to model adhesively bonded joints, the Cohesive Zone Model (CZM) is widely used because of its relatively easy application and simulation capability of joints [22]. Campilho et al. [23] inspected triangular, trapezoidal and exponential CZMs and concluded that although triangular CZM has been used most, all of these models predict mechanical 
properties in a narrow error range. May et al.[24] compared experimental and CZM analysis results with regards to the rate dependency of epoxy adhesive. They found that there is a good agreement between the experiment and the CZM. Trimino et al.[12] utilized DP460NS adhesive to find cohesive zone parameters and reported linear fits for tensile and shear strength of adhesive for different strain rates. They made some assumptions on determining the fracture behavior of adhesive. While they proposed linear fits for tensile and shear for different rates, they did not provide the same strain rate dependence for $\mathrm{G}_{\mathrm{I}}$ and $\mathrm{G}_{\mathrm{II}}$. Even these assumptions lower the accuracy of the method, it provides an estimation of mechanical behavior of the adhesive joint.

This study aims to investigate the strain rate dependency of the single lap joint by using different metal adherents. As an experimental preliminary study, it was focused on finding suitable surface preparation methods, adhesive thickness and curing pressure which all of them reported above as factors that affect joint strength. SEM and AFM images were taken to analyze adhesive fracture surface and adherent surface qualities. Subsequently, different strain rates have been employed in the study to determine the behavior of both adhesive (DP460NS, 3M) and Aluminum/Steel adherents. Lastly, CZM was employed to conduct finite element analysis. Results of experimental and FEA were compared. Stress and deformation characteristics of joints, which were obtained from FEA, used to clarify the strain rate dependency of mono- and bi-material joints.

\section{MATERIAL AND METHOD}

\section{Determining optimal adhesive thickness under constant pressure}

7 here are numerous researches to determine optimum adhesive thickness. In order to determine the optimum thickness and cure pressure, 3 tests have been conducted with constant pressure $(200 \mathrm{kPa})$. Firstly, it has been conducted using thin foil (around $0.05 \mathrm{~mm}$ ) apparatus. Secondly, a steel film that has $0.25 \mathrm{~mm}$ thickness has been placed to upper and lower plates of single lap joint. Lastly, flame resistant tape has been placed to joints to achieve $0.13 \mathrm{~mm}$ thickness. Then constant pressure has been applied during curing.

\section{Determining the surface preparation method}

Aluminum samples have been sanded by SiC sandpaper up to 600, 1200 and 4000 then conducted tests. Surface roughness was examined for three surfaces by using Atomic Force Microscopy (AFM). The grinding process was repeated for steel substrates to obtained similar surface roughness as aluminum.

\section{Sample preparation and test procedure}

After the sanding process, samples were washed in acetone then dried by hot air. The fixture for the accelerated curing process was prepared and numbered. For each batch, 6 samples were located to the fixture. It was placed to the oven at cure temperature. The technical sheet of adhesive manufacturer suggests full heat accelerated cure for $60 \mathrm{~min}$ at $66{ }^{\circ} \mathrm{C}$ [25]. After the curing process, samples were kept at room temperature for $24 \mathrm{~h}$ before tests.

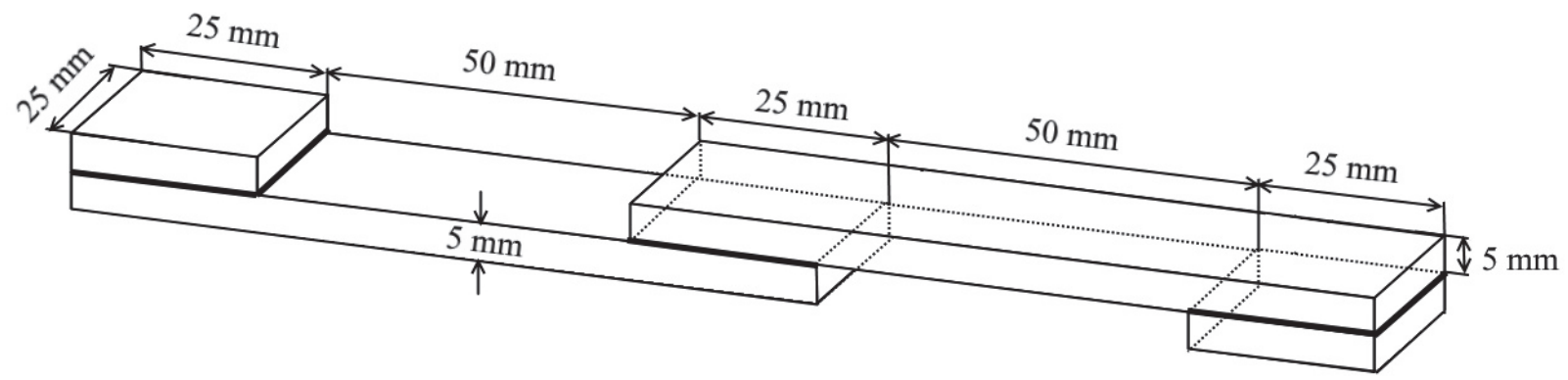

Figure 1: The Geometry of single lap joint

7075-T7 aluminum and 304 steel were selected as adherends. Three different configurations were established by using aluminum-aluminum (AA), steel-steel (SS) and aluminum-steel (AS) materials. These adherends were bonded by Scotch- 
Weld ${ }^{\mathrm{TM}}$ Epoxy Adhesives DP460NS (3M, 2017). Tab. 1 presents material properties. SLJ geometry for the ASTM D1002 [26] test is given in Fig. 1.

\begin{tabular}{lccc}
\hline Material & E (GPa) & $\nu$ & Tensile Strength (MPa) \\
AL 7075 T7 & 72 & 0.33 & 500 \\
SAE 304 & 193 & 0.29 & 505 \\
DP460NS & 2.13 & 0.41 & 46 \\
\hline
\end{tabular}

Table 1: Mechanical properties of Al-7075 T7, SAE 304 [27] and the DP 460NS [12]

SLJs have been tested by using the Instron 8801 testing system (Fig. 2) for each strain rate. ASTM D1002 suggests testing shear strength of metal-metal SLJs by using $1.3 \mathrm{~mm} / \mathrm{min}( \pm 0.3 \mathrm{~mm} / \mathrm{min})$ crosshead speed. For 1, 10, 25 and $50 \mathrm{~mm} / \mathrm{min}$ displacement rates and material combinations, 6 repeats have been performed. From those repeats for some displacement rates for SS joints, at most one result ignored, which was considered wrong, to ensure consistent calculations. Those repeated force-displacement curves have been fitted by using linear regression approach. To sake of simplicity, material and strain rate combinations were coded and presented as Tab. 2.

\begin{tabular}{lcccc} 
& & & \\
Saterial & $1 \mathrm{~mm} / \mathrm{min}$ & $10 \mathrm{~mm} / \mathrm{min}$ & $25 \mathrm{~mm} / \mathrm{min}$ & $50 \mathrm{~mm} / \mathrm{min}$ \\
Aluminum & AA-1 & AA-10 & AA- 25 & AA-50 \\
Steel & SS-1 & SS-10 & SS-25 & SS-50 \\
Aluminum-Steel & AS-1 & AS-10 & AS-25 & AS-50 \\
\hline
\end{tabular}

Table 2: Test group names.

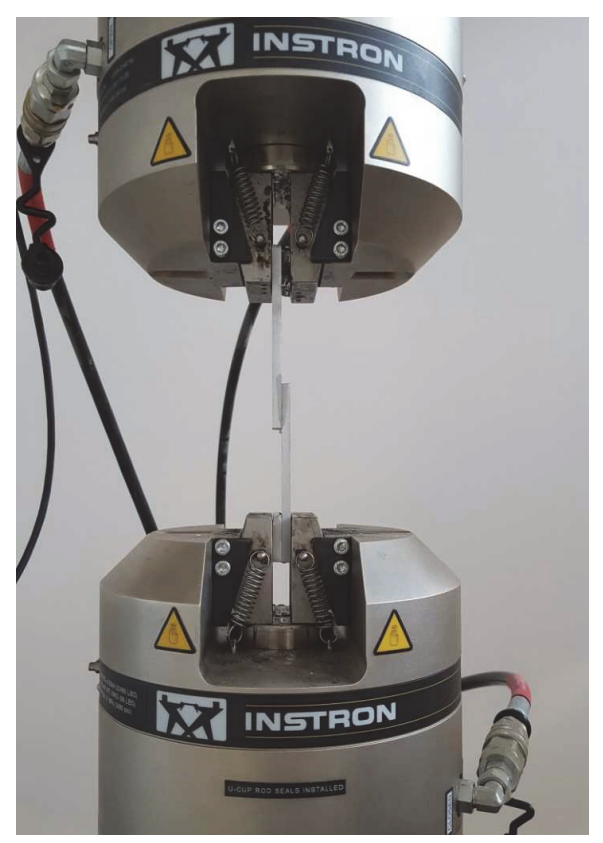

Figure 2: SLJ sample placement at Instron 8801 test machine 
After conducting uniaxial tensile tests, failure adhesive surfaces have been investigated by FEI Quanta FEG 450 scanning electron microscopy (SEM).

\section{Preparing finite element analysis}

Finite element analysis has been conducted using ANSYS 18.0 commercial analysis software. For analysis, the full threedimensional (3D) SLJ model has been employed (Fig. 3). Adhesive and adherents have been defined by elastoplastic model. Zero thickness cohesive elements for adhesive layer has modeled using Bilinear Material Behavior with Tractions and Critical Fracture Energies. The main advantage of using cohesive zone model is that, analysis does not require information about crack. The cohesive zone model uses the relation between traction and separation to predict crack initiation [14]. In this study mixed-mode debonding involves both normal separation and tangential slip implemented infinite element analysis to obtain failure loads.

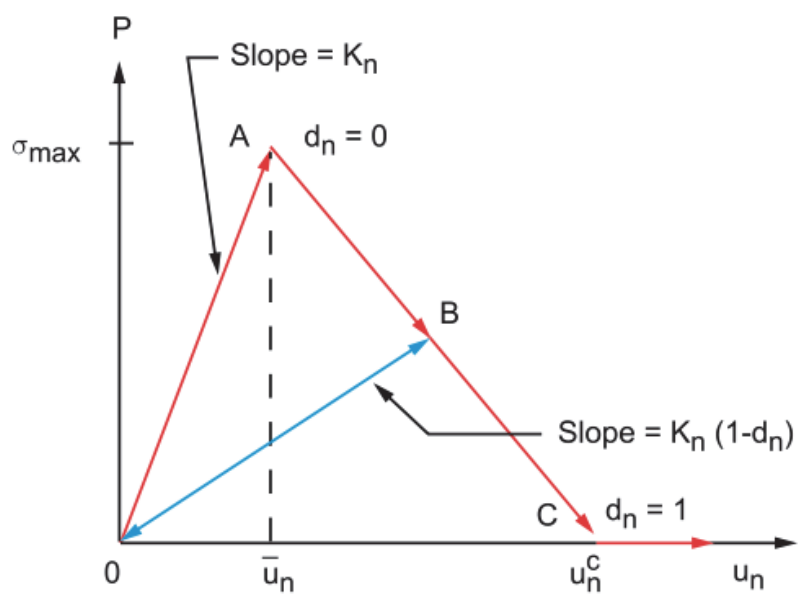

Figure 3: Normal Contact Stress and Contact Gap Curve for Bilinear Cohesive Zone Material [28]

In mixed-mode debonding the interface separation depends on both normal and tangential components. The equations for the normal and the tangential contact stresses are written as:

$$
P=K_{n} u_{n}\left(1-d_{m}\right)
$$

$\mathrm{P}=$ normal contact stress (tension)

$\mathrm{K}_{\mathrm{n}}=$ normal contact stiffness

$\mathrm{u}_{\mathrm{n}}=$ contact gap

$\mathrm{d}_{\mathrm{m}}=$ debonding parameter

and

$$
\tau_{t}=K_{t} u_{t}\left(1-d_{m}\right)
$$

The debonding parameter is defined as:

$$
d_{m}=\left(\frac{\Delta_{m}-1}{\Delta_{m}}\right) X
$$

With $\mathrm{d}_{\mathrm{m}}=0$ for $\Delta_{\mathrm{m}} \leq 1$ and $0<\mathrm{d}_{\mathrm{m}} \leq 1$ for $\Delta_{\mathrm{m}}>1$, and $\Delta_{\mathrm{m}}$ and $\mathrm{X}$ are:

$$
\Delta_{m}=\sqrt{\Delta_{n}^{2}+\Delta_{t}^{2}}
$$




$$
X=\left(\frac{u_{n}^{c}}{u_{n}^{c}-\bar{u}_{n}}\right)=\left(\frac{u_{t}^{c}}{u_{t}^{c}-\bar{u}_{t}}\right)
$$

The constraint on $\mathrm{X}$ that the ratio of the contact gap distances is the same as the ratio of tangential slip distances is enforced automatically by appropriately scaling the contact stiffness value, $K_{t}$, as follows:

$$
K_{t}=\left(\frac{\tau_{\max } u_{n}^{c}}{\sigma_{\max } u_{t}^{c}}\right) K_{n}
$$

For mixed-mode debonding, both normal and tangential contact stresses contribute to the total fracture energy and debonding is completed before the critical fracture energy values are reached for the components. Therefore, a power lawbased energy criterion is used to define the completion of debonding:

$$
\left(\frac{G_{n}}{G_{c n}}\right)^{2}+\left(\frac{G_{t}}{G_{c t}}\right)^{2}=1
$$

where:

$$
\begin{aligned}
& G_{n}=\int P d u_{n} \\
& G_{t}=\int \tau_{t} d u_{t}
\end{aligned}
$$

are, respectively, the normal and tangential fracture energies [28].

All elements in FEA analysis were modeled using the SOLID186 20-node element type which has quadratic displacement behavior. CONTA174 was used to represent contact and sliding between 3D and deformable surfaces [29]. Considering mesh quality and stress concentration of adhesive, model was divided into 3 sections (Fig. 4). First and third sections for non-adhesive adherents which were modeled fine to course elements from adhesive line to end of the part. The second section is the lap area which was also modeled fine at near edges and coarse mesh at middle. With using this set of mesh properties, it was purposed to eliminate singularity zones.

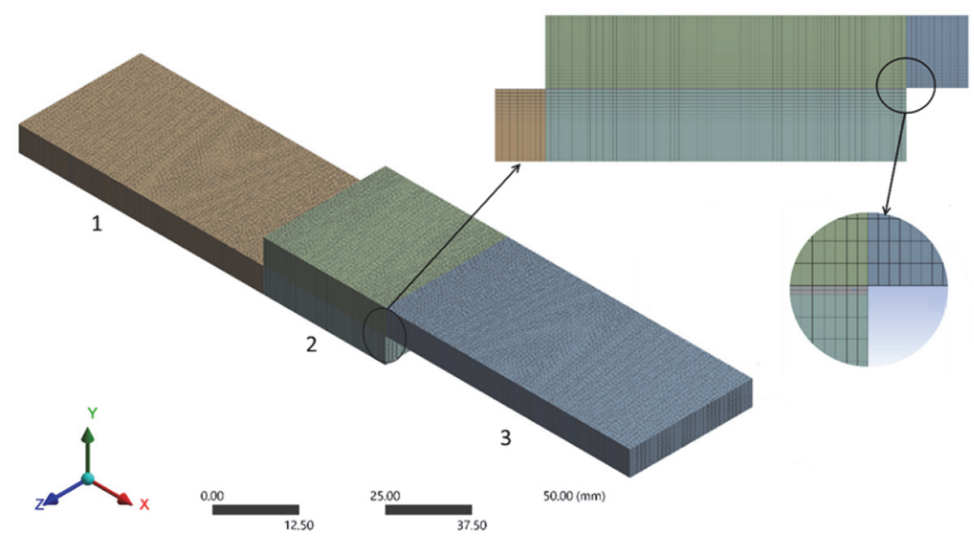

Figure 4: FEA model and mesh structure

Mesh size was adopted as half of the adhesive thickness due to CZM and failure load is not strongly tied to mesh size [30,31]. The average element quality and aspect ratio were observed as 0.97 and 1.21 respectively. CZM parameters for DP460NS under different strain rates were introduced at Trimino et al.'s [12] study. Values for critical fracture energy for normal and shear separation were taken from this study. 
Figure 5 shows the boundary conditions of the analysis. The model was only allowed to displace through $\mathrm{x}$-direction till failure. Stresses were derived from point A which is on the center top of the adhesive layer as shown in Fig. 6.



Figure 5: Boundary conditions of single lap joint

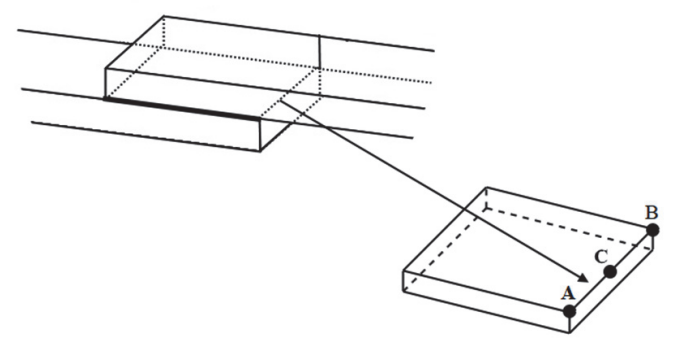

Figure 6: Critical points in the adhesive layer

\section{RESULTS AND DISCUSSIONS}

Determining joint surface and adhesive thickness

ifferent SS and AA surface quality were investigated. Results have been given in Fig. 7 for aluminum specimens. According to these results, from 600-grit to 1200-grit, there was an increase but from 1200-grit to 4000-grit there was not a significant improvement at failure loads. Also, for 4000-grit surface, results from samples had more fluctuation than 1200-grit surface. For this reason, 1200- grit SiC paper was employed for aluminum specimens.

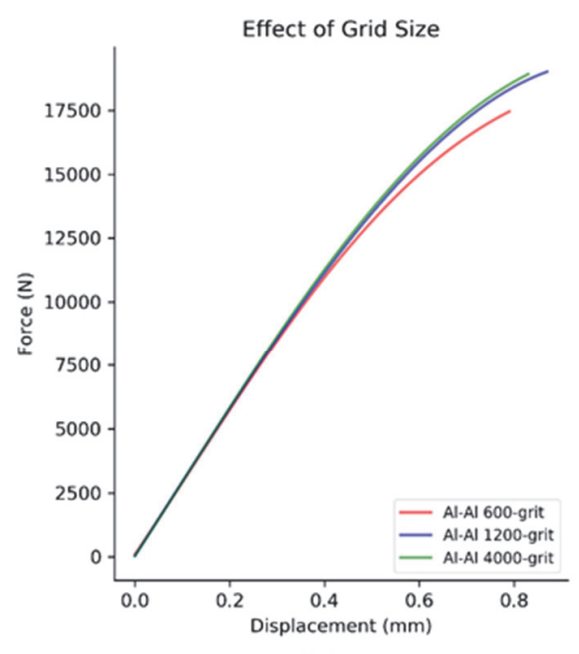

(a)

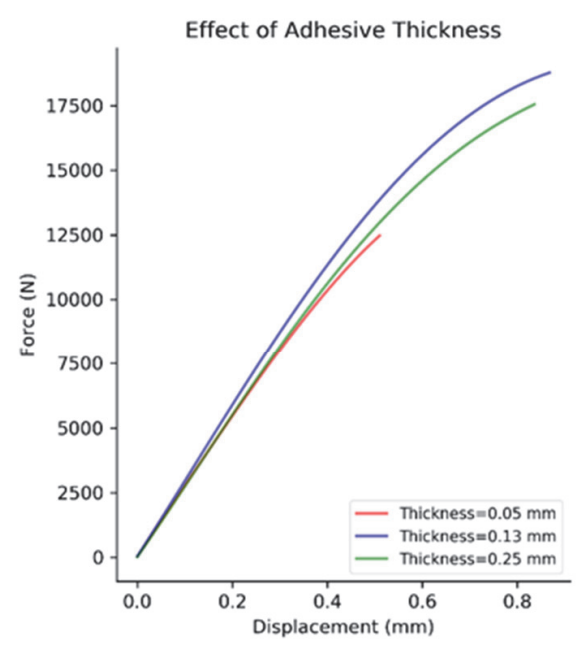

(b)

Figure 7: Failure load, a) Effect of the grit size b) Effect of adhesive thickness 
AFM results for aluminum surfaces have been given in Fig. 8 (a-b-c). From this figure, while sandpaper grit size increases, surface roughness decrease. Surface roughnesses were calculated as 281, 193, $81 \mathrm{~nm}$ for 600-, 1200- and 4000-grit SiC papers respectively. It is observed that failure loads are not affected by surface roughness's which is smaller than $200 \mathrm{~nm}$. For steel substrates, surface roughness was kept lower than $200 \mathrm{~nm}$. AFM result for steel substrates is given in Fig. 8 (d). Surface roughness affects failure load of adhesive. When compared to surface roughness of aluminum samples, for 600-grit size, increase in surface roughness could act as a notch. Roughness becomes better at 1200-grit and failure loads increases. However, a significant difference was not observed at 4000-grit surface due to the smoothness of the adherend surfaces. This shows that adhesion was not affected by surface quality after 1200-grit sandpaper.
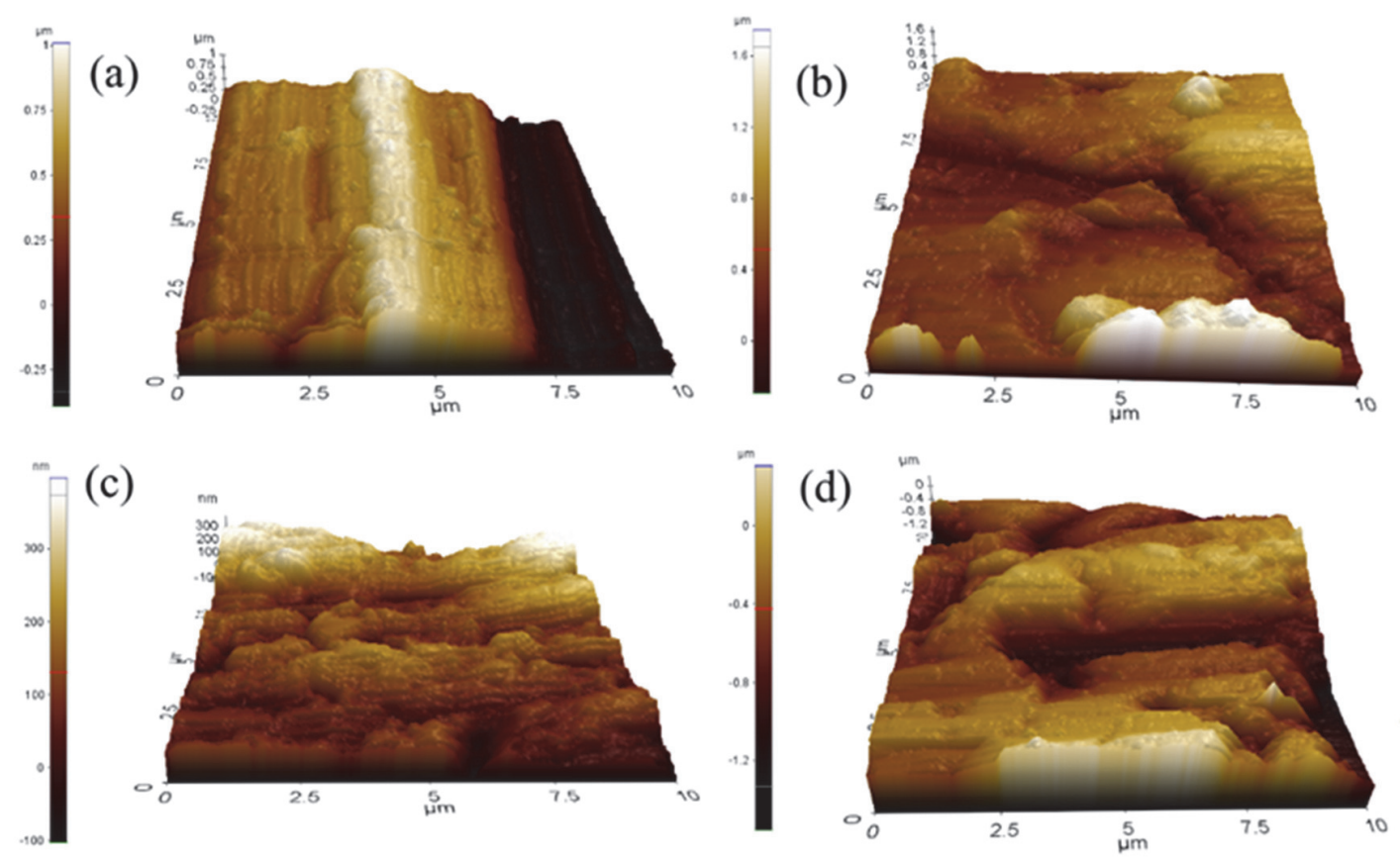

Figure 8: AFM images of adherent surfaces

To determine optimum adhesive thickness, three thickness was selected for AA substrates that have 1200-grit sandpapered surfaces. For first thickness, mean failure load was noted as $12.489 \mathrm{kN}$ and mean adhesive thickness was measured as 0.05 $\mathrm{mm}$. Secondly, for $0.13 \mathrm{~mm}$ thickness $18.736 \mathrm{kN}$ failure load was measured. Lastly, adhesive thickness was increased to 0.25 $\mathrm{mm}$ and failure load decreased to $17.370 \mathrm{kN}$. Considering these results and literature [32], $0.13 \mathrm{~mm}$ adhesive thickness was selected for rest of tests.

From literature, while thickness increases, the failure load of adhesive decreases. From results, when adhesive thickness was increased from $0.05 \mathrm{~mm}$ to $0.13 \mathrm{~mm}$, failure loads increased. For higher thicknesses, possibility to contain micro defects and cracks in adhesive layer, adhesive strength decreases for $0.25 \mathrm{~mm}$ [14]. From these results, an optimum thickness was found as $0.13 \mathrm{~mm}$ and this has good agreement with Campilho et al.'s propositions [33].

\section{Experimental result of SLJs}

For DP460NS epoxy adhesive, experiments with bulk adhesive showed that adhesive strength increases by displacement rate. This behavior was observed from SLJ test results as shown in Fig. 9 [12]. For $1 \mathrm{~mm} / \mathrm{min}$, the best result obtained from AA-1. Above this displacement rate, SS joints presented greater strength when compared to other types of joints.

AA, SS and AS joints have been compared by displacement rates in Fig. 9. For each joint type, increasing strain rate leads to time-dependent deformation and enhances failure loads. Consequently, stress-relaxation occurs after failure peak point. In general, increasing displacement rate promotes displacement. For AA and AS joints, although curves followed the same paths, failure loads and displacements were different.

Apart from metals that increasing strain rate provoke both stress and strain, polymers have different behavior. Polymers have more free volume than metals that enables more strain capability and increase affinity to time-dependent deformation [34]. This unexpected result at displacements for epoxy polymers was reported by Goldberg [35] that explains difficulties to escalate the expected strain rate for lower rates. While strain rate increases, for SS-50 joints, the highest displacement ensures the maximum failure load among all groups. 
Experimental and numerical results of force-displacement curves for AA, AS, SS joint combinations at different displacement rates are introduced in Fig. 10. Displacement and failure load values are shown in Tab. 3.


Figure 9: Experimental results of same test groups a) AA b) SS c) AS


Figure 10: Failure loads of experimental and numerical analysis. Displacement rates a) $1 \mathrm{~mm} / \mathrm{min} \mathrm{b}) 10 \mathrm{~mm} / \mathrm{min} \mathrm{c}) 25 \mathrm{~mm} / \mathrm{min} \mathrm{d}) 50$ $\mathrm{mm} / \mathrm{min}$

For $1 \mathrm{~mm} / \mathrm{min}$ it could be seen from Fig. 10(a), while steel-steel joint has been exhibited lower failure load and displacement, AA joints have been presented higher failure load for this rate. It has been observed that AA-1, SS-1, AS-1 failed at 18.948 $\mathrm{kN}, 17.395 \mathrm{kN}$, and $18.346 \mathrm{kN}$ respectively. AS-1 exhibited 5.46\%, AA-1 showed 8.9\% higher failure loads respect to SS-1 
joints. These results had good agreement with adhesive manufacturers Technical Data Sheet [25]. From Fig. 10(a), AA-1 joint has the highest displacement which is $0.86 \mathrm{~mm}$ and it reaches this displacement in 51.6 seconds, these values for AS1 are $0.70 \mathrm{~mm}$ and $42 \mathrm{~s}$ and for SS-1 are $0.50 \mathrm{~mm}$ and 30s. Joints that have aluminum substrate exhibits higher failure loads due to the elastic strain of material around joint areas. During SLJs tests, due to aluminum's higher distortion capability, it keeps adhesive together and increases the area of applied stress. This lowers time-dependent stress and increases failure loads $[36,37]$.

\begin{tabular}{|c|c|c|c|c|c|c|c|c|c|}
\hline & \multicolumn{3}{|c|}{$\begin{array}{c}\text { Experimental Results } \\
\text { AA }\end{array}$} & \multicolumn{3}{|c|}{$\begin{array}{l}\text { Experimental Results } \\
\text { SS }\end{array}$} & \multicolumn{3}{|c|}{$\begin{array}{c}\text { Experimental Results } \\
\text { AS }\end{array}$} \\
\hline & $\begin{array}{c}\text { Failure } \\
\text { Load }(\mathrm{kN})\end{array}$ & $\begin{array}{l}\text { Disp. } \\
(\mathrm{mm})\end{array}$ & $\begin{array}{l}\text { Duration } \\
\text { (s) }\end{array}$ & $\begin{array}{c}\text { Failure } \\
\text { Load }(\mathrm{kN})\end{array}$ & $\begin{array}{l}\text { Disp. } \\
(\mathrm{mm})\end{array}$ & $\begin{array}{l}\text { Duration } \\
\text { (s) }\end{array}$ & $\begin{array}{c}\text { Failure } \\
\text { Load }(\mathrm{kN})\end{array}$ & $\begin{array}{l}\text { Disp. } \\
(\mathrm{mm})\end{array}$ & $\begin{array}{l}\text { Duration } \\
\text { (s) }\end{array}$ \\
\hline $1 \mathrm{~mm} / \mathrm{min}$ & 18.948 & 0.86 & 52 & 17.395 & 0.5 & 30 & 18.346 & 0.70 & 42 \\
\hline $10 \mathrm{~mm} / \mathrm{min}$ & 19.399 & 0.83 & 4.98 & 20.134 & 0.59 & 3.54 & 19.257 & 0.70 & 4.2 \\
\hline $25 \mathrm{~mm} / \mathrm{min}$ & 21.177 & 0.96 & 2.3 & 21.642 & 0.76 & 1.82 & 20.199 & 0.76 & 1.82 \\
\hline $50 \mathrm{~mm} / \mathrm{min}$ & 22.204 & 1.15 & 1.38 & 22.566 & 1.18 & 1.41 & 20.800 & 0.87 & 1.04 \\
\hline
\end{tabular}

Table 3: Experimental failure loads, displacements and durations.

For displacement rates that were higher than $1 \mathrm{~mm} / \mathrm{min}$, SS joints showed higher failure loads. At $10 \mathrm{~mm} / \mathrm{min}$ displacement rate, AA-10 exhibited $0.73 \%$ and SS-10 presented $4.5 \%$ higher failure loads with respect to AS- 10 . At $25 \mathrm{~mm} / \mathrm{min}$, while AS-25 showed lowest failure load, AA-25 exhibited 4.8\% and SS-25 displayed 7.14\% higher failure loads than AS-25. At 50 $\mathrm{mm} / \mathrm{min}$, while AS-50 presented lowest failure load, AA-50 exhibited $6.75 \%$ and SS-25 displayed $8.49 \%$ higher failure loads than AS-50.

It could be seen from Fig. 10, experiments were almost coincident with the finite element analysis that was done by using CZM model and errors have been observed less than $1 \%$.

From Fig. 14, while displacement rates increased, for three test setups, deformation in y-direction at adhesion area decreased. As a result, in region $\mathrm{A}$, shear stress decreased due to the fact that failure load increased. From Fig. 12, failure started from region A could grow and adhesive failure occurred on both sides at $1 \mathrm{~mm} / \mathrm{min}$. For $50 \mathrm{~mm} / \mathrm{min}$, region A could not grow fast enough, adhesive could not deform as expected adhesive behavior and this caused adhesive failure only one side of metal [18].

Another reason for increasing failure loads is the lower duration of failure because craze in polymer structures could not initiate cracks. SEM images of adhesive fractured surfaces have been given in Fig. 11 (a - b). From these images, for lower displacement rates as $1 \mathrm{~mm} / \mathrm{min}$, crazes found time to initiate cracks hence this caused adhesive fractures at both sides of metal substrates (Fig. 11(a)). While displacement rate was increasing to $50 \mathrm{~mm} / \mathrm{min}$, fractures occurred suddenly thus it showed less deformation in adhesive. (Fig. 11(b))

Fig. 11 (c) shows adhesive deformation along y-direction. Fig. 11(d), crack area contain voids was wider than other cracks. This showed that main cracks started from region which has voids. Adhesive surfaces after tests are given in Fig. 12. For each specimen, main failure mechanism is adhesive failure. However, there are some cohesive failure zones around the edges of the residual adhesive layer. For $1 \mathrm{~mm} / \mathrm{min}$ displacement rate, both upper and lower adherend has residual adhesive layer after failure. For $50 \mathrm{~mm} / \mathrm{min}$ displacement rate, adhesive layer shows a tendency to stick one of the adherends. This behavior can be explained by the increase of displacement rate which is responsible for fast cracks formed in the adhesive layer.

Fig. 13 shows the comparison of SLJs failure loads for different setups. In this figure, bars show failure loads and triangles express maximum equivalent stress at the end of linear displacement of point $C$ for joints (Fig. 6). While failure loads were gradually increased by displacement rates for each material group, it was observed that stresses in adhesives decreased. The highest stress, around $50 \mathrm{MPa}$ occurred at SS-1 joint which has lowest failure load. The lowest stress, nearly $32.5 \mathrm{MPa}$, occurred at AA-50 joint. Failure loads increased similar to experimental results. While displacement rates were increasing, failure loads increase rose as well [38]. This increment in failure load could be explained by lower deformation at $Y$ direction (Fig. 14). 


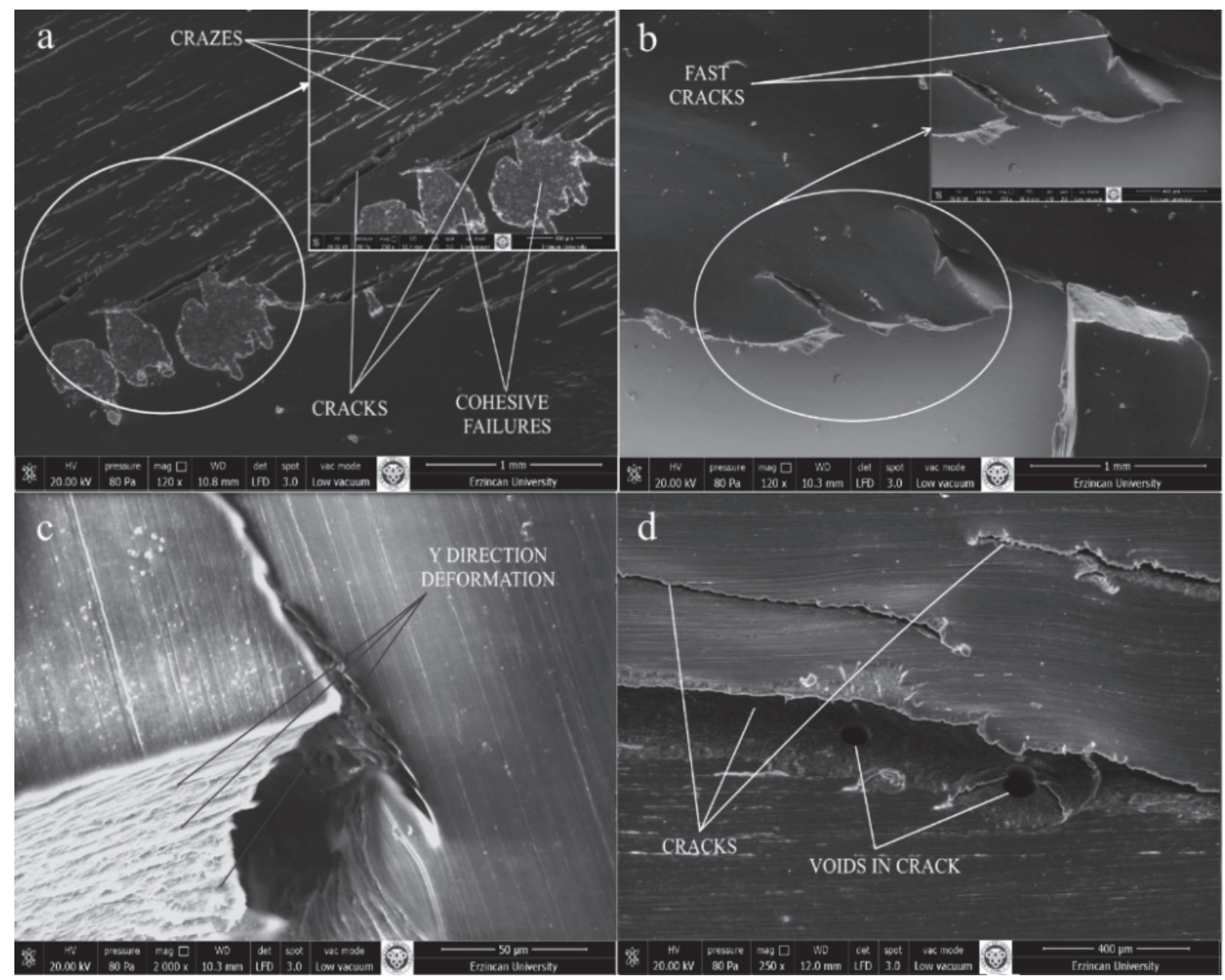

Figure 11: SEM images of adhesive fracture surfaces a) AS-1 b) AS-50 c) AA-1 d) AA-50.

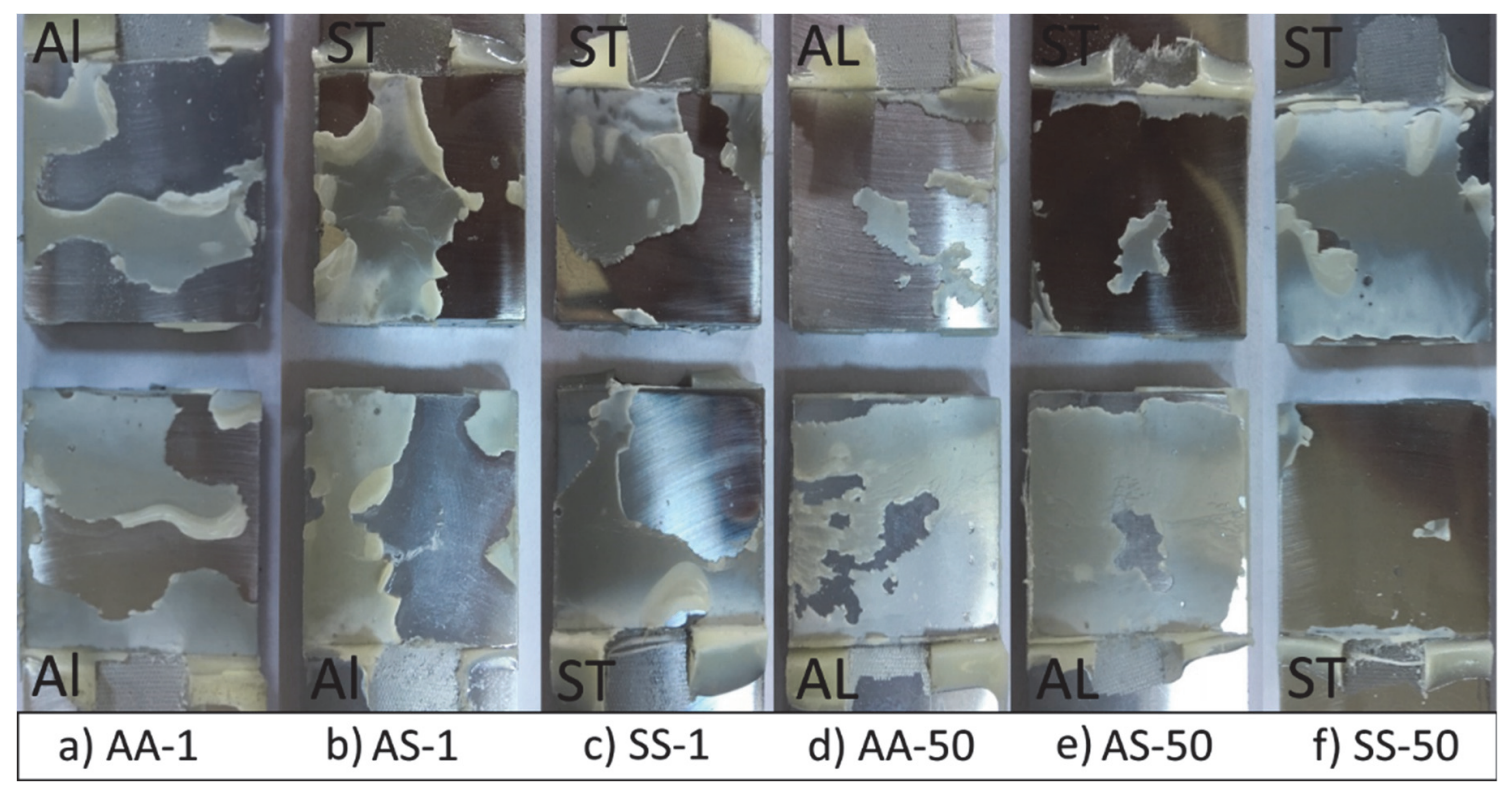

Figure 12: SEM images of adhesive fracture surfaces a) AS-1 b) AS-50 c) AA-1 d) AA-50 


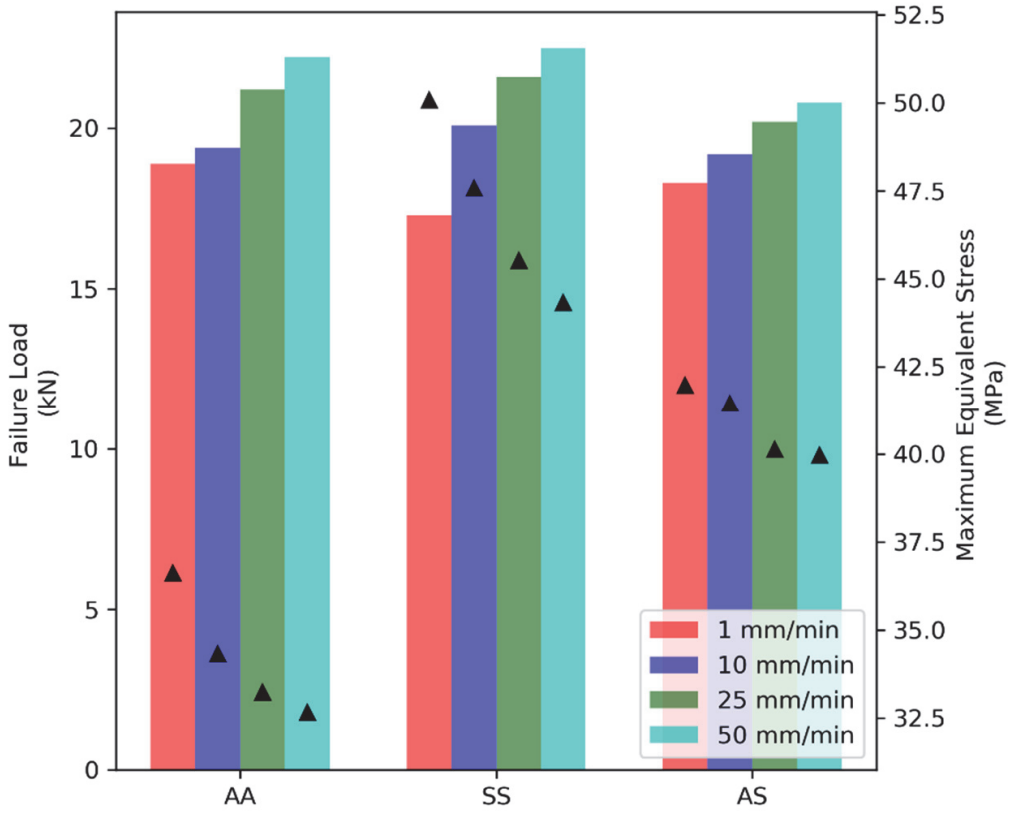

Figure 13: FEA stresses and failure loads of adhesive

The increase in stresses depending on the type of material could be explained by Young modulus mismatch phenomenon. When the ratio between Young modulus of adherents increases, this difference between the two materials causes an increment at stress. The complexity of Eigenvalues increases the singularity consequently stress concentration factor escalates $[39,40]$. Stresses on the AS joints occur between AA and SS because of this mismatch of joints.

From Fig. 14, while displacement rates rise, for three test setups, y-directional deformation at adhesive decreases. As a result, at point $C$, failure load improves since shear stress falls. From Fig. 12, failure starts from point $C$ then grow finally adhesive fails on both sides at $1 \mathrm{~mm} / \mathrm{min}$. For $50 \mathrm{~mm} / \mathrm{min}$, point $C$ could not grow fast enough, the adhesive could not deform as expected consequently this causes adhesive failure only one side of adherend [18].

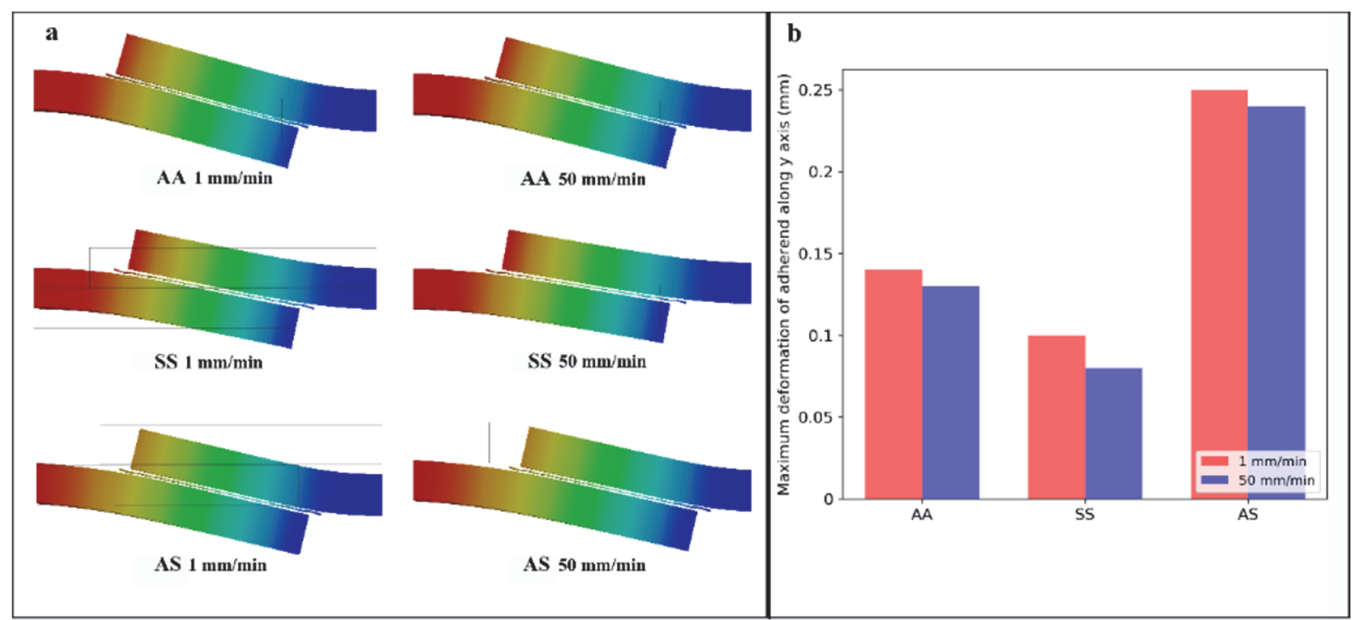

Figure 14: a) Y-directional deformation of FEA b) Y-directional deformation values

Fig. 15 shows peel and shear stresses that occur at adhesive layer. From peel stresses in adhesive layer, it could be seen that almost 5\% decreased for each material group. Also, highest peel stress occurred at AS-1 joint which was distinction from overall behavior of this group. Deformation in $\mathrm{Y}$ direction reached the highest value for AS joints and this increased peel stresses (Fig. 14). In AA joints, deformation was handled by two aluminum, in SS joints, deformation at Y direction was lowered because two steel were handled deformation but in AS joints steel did not deform as expected and most deformation was handled by aluminum. This increased $\mathrm{Y}$ direction deformation and increase peel stress. 
For comparison of shear stresses, which is an essential mechanical property for SLJs, there was a dramatic decrease for AA compared to SS joints. While there is no significant difference between failure loads of these joints, there was almost $37 \%$ increase in shear stress in reference to AA joints. Lowest deformation in Y direction occurred at SS joints and this increased shear stress in adhesive.

\begin{tabular}{|c|c|c|c|c|c|c|}
\hline & \multicolumn{2}{|c|}{$\begin{array}{c}\text { FEA Results } \\
\text { AA }\end{array}$} & \multicolumn{2}{|c|}{$\begin{array}{c}\text { FEA Results } \\
\text { SS }\end{array}$} & \multicolumn{2}{|c|}{$\begin{array}{c}\text { FEA Results } \\
\text { AS }\end{array}$} \\
\hline & $\begin{array}{l}\text { Failure Load } \\
\qquad(\mathrm{kN})\end{array}$ & $\begin{array}{l}\text { Displacement } \\
(\mathrm{mm})\end{array}$ & $\begin{array}{l}\text { Failure Load } \\
\qquad(\mathrm{kN})\end{array}$ & $\begin{array}{l}\text { Displacement } \\
(\mathrm{mm})\end{array}$ & $\begin{array}{l}\text { Failure Load } \\
\qquad(\mathrm{kN})\end{array}$ & $\begin{array}{c}\text { Displacement } \\
(\mathrm{mm})\end{array}$ \\
\hline $1 \mathrm{~mm} / \mathrm{min}$ & 18.952 & 0.92 & 17.295 & 0.52 & 18.464 & 0.73 \\
\hline $10 \mathrm{~mm} / \mathrm{min}$ & 19.359 & 0.87 & 20.038 & 0.62 & 19.206 & 0.73 \\
\hline $25 \mathrm{~mm} / \mathrm{min}$ & 21.110 & 0.99 & 21.608 & 0.78 & 20.423 & 0.79 \\
\hline $50 \mathrm{~mm} / \mathrm{min}$ & 22.250 & 1.22 & 22.503 & 1.193 & 20.639 & 0.89 \\
\hline
\end{tabular}

Table 4: FEA failure loads and X-directional deformation values
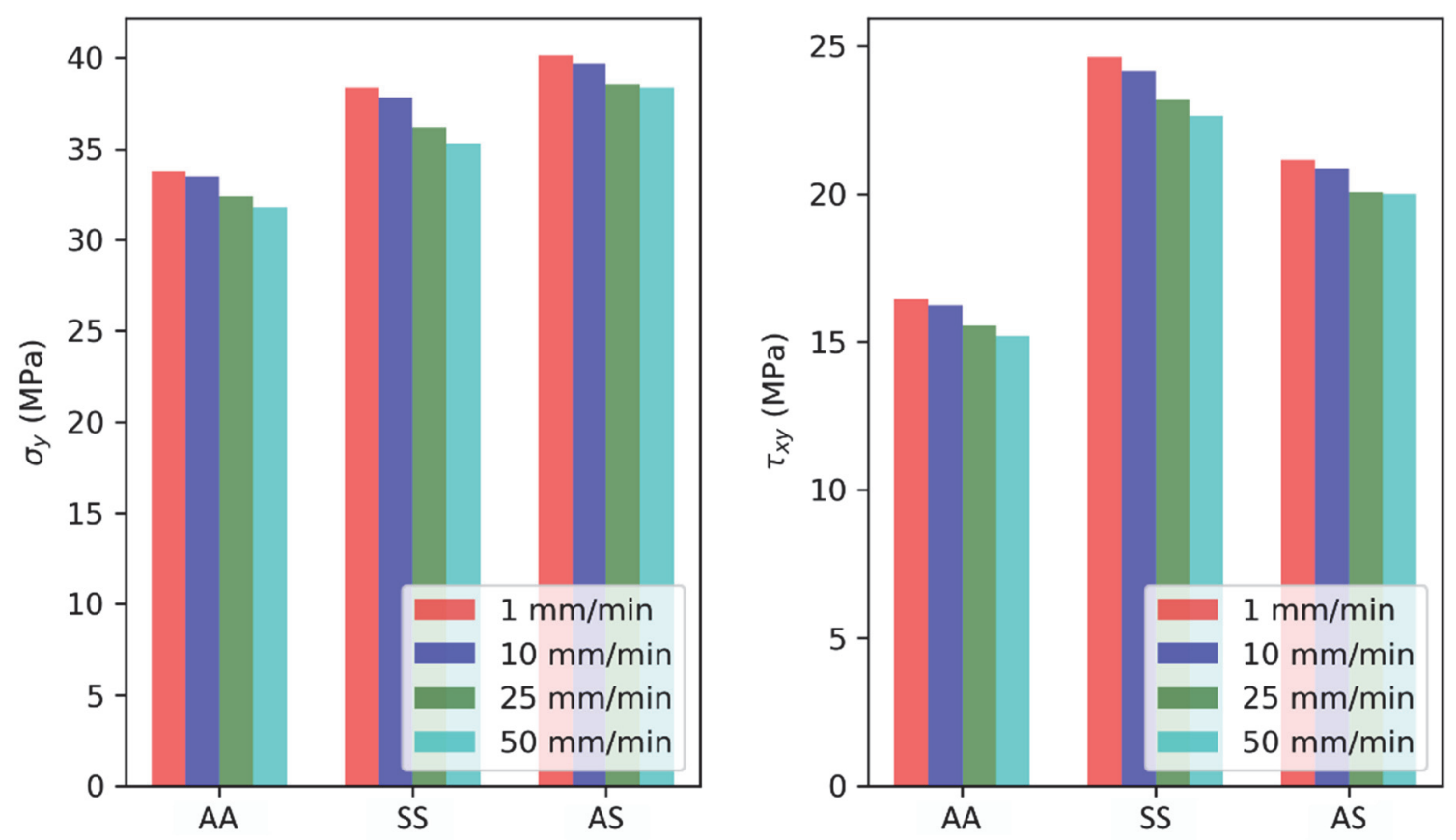

Figure 15: Peel and Shear Stress in adhesive values

\section{CONCLUSION}

$\mathrm{I}$

$\mathrm{n}$ this study, aluminum, steel, and aluminum-steel SLJs were bonded by using DP460NS epoxy adhesive and tested at different displacement rates. Joints surfaces and thickness were optimized to achieve the highest failure loads. Results are given as follows:

1. In order to determine the effect of surface roughness, different surface roughness was examined using AFM. Failure loads were not affected surface roughness's lower than $200 \mathrm{~nm}$.

2. Before tensile testing of adhesive joints under different displacement rates, three different adhesive thickness were investigated. Optimum adhesive thickness was determined as $0.13 \mathrm{~mm}$. 
3. For all test groups, failure loads increased by increasing displacement rates. For $1 \mathrm{~mm} / \mathrm{min}$, the highest failure load was obtained from AA joint. For displacement rates higher than $1 \mathrm{~mm} / \mathrm{min}$, the highest performance was observed at SS joints.

4. Maximum deformation along y-direction occurred at AS joints hence it resulted maximum peel stress. For SS joints, since steel has lowest deformation in $\mathrm{y}$-direction it exhibits higher shear stress. This increase for steel was also related to Young modulus mismatch phenomenon.

5. According to SEM images; crazes, which evolved cracks observed at lower displacement rates. Fast fractures were observed at higher displacement rates. Additionally, it was shown that micro-cracks initiated from voids in the adhesive layer. Deformation along y-direction in adhesive layers observed in SEM images as well.

6. It was found that the adhesive has rate dependency even lower strain rates.

To sum up, the results showed that increasing displacement rate affected the performance of the joints positively. Although the standard SLJ test procedure suggests lower displacement rates, it was concluded that joint strength was affected by material properties while increasing the displacement rate. Results could give an insight into the rate dependency of the adhesive joint under low displacement rates. In addition to this, it was pointed out surface roughness and adhesive thickness were essential parameters that have an influence on adhesive strength.

\section{ACKNOWLEDGMENT}

$\mathrm{F}$ unding: This work was supported by the research fund of the Erzincan Binali Yıldırım University [Grant number FHD-2017-530].

\section{REFERENCES}

[1] Wu, W., Liu, Q., Zong, Z., Sun, G., Li, Q. (2013). Experimental investigation into transverse crashworthiness of CFRP adhesively bonded joints in vehicle structure, Compos. Struct., 106, pp. 581-589,

DOI: 10.1016/j.compstruct.2013.07.009.

[2] Raykhere, S.L., Kumar, P., Singh, R.K., Parameswaran, V. (2010). Dynamic shear strength of adhesive joints made of metallic and composite adherents, Mater. Des., 31(4), pp. 2102-2109, DOI: 10.1016/j.matdes.2009.10.043.

[3] Carvalho, U.T.F., Campilho, R.D.S.G. (2017). International Journal of Adhesion and Adhesives Validation of pure tensile and shear cohesive laws obtained by the direct method with single-lap joints, Int. J. Adhes. Adhes., 77, pp. 4150, DOI: 10.1016/j.ijadhadh.2017.04.002.

[4] Akpinar, S. (2014). The strength of the adhesively bonded step-lap joints for different step numbers, Compos. Part B Eng., 67, pp. 170-178, DOI: 10.1016/j.compositesb.2014.06.023.

[5] Akpinar, I.A., Gültekin, K., Akpinar, S., Akbulut, H., Ozel, A. (2017). Experimental analysis on the single-lap joints bonded by a nanocomposite adhesives which obtained by adding nanostructures, Compos. Part B Eng., 110, pp. 420428, DOI: 10.1016/j.compositesb.2016.11.046.

[6] Bamberg, P.A.M.G.P., Reisgen, U., Schiebahn, A., Barbosa, J.D.V., Marx, B., Coelho, R.S. (2018). Digital Image Correlation Analysis Of The Effects Of The Overlap Length, Adhesive Thickness And Adherends Yield Strength Over Similar And Dissimilar Joints Of High Strength Steel And Aluminum Alloys, Int. J. Adhes. Adhes., 83(March), pp. 6975, DOI: 10.1016/j.ijadhadh.2018.02.010.

[7] Razavi, S.M.J., Ayatollahi, M.R., Nemati Giv, A., Khoramishad, H. (2018). Single lap joints bonded with structural adhesives reinforced with a mixture of silica nanoparticles and multi walled carbon nanotubes, Int. J. Adhes. Adhes., 80(October 2017), pp. 76-86, DOI: 10.1016/j.ijadhadh.2017.10.007.

[8] Gülltekin, K., Akpinar, S., Gürses, A., Eroglu, Z., Cam, S., Akbulut, H., Keskin, Z., Ozel, A. (2016). The effects of graphene nanostructure reinforcement on the adhesive method and the graphene reinforcement ratio on the failure load in adhesively bonded joints, Compos. Part B Eng., 98, pp. 362-369, DOI: 10.1016/j.compositesb.2016.05.039.

[9] Reis, P.N.B., Ferreira, J.A.M., Antunes, F. (2011). Effect of adherends rigidity on the shear strength of single lap adhesive joints, Int. J. Adhes. Adhes., 31(4), pp. 193-201, DOI: 10.1016/j.ijadhadh.2010.12.003.

[10] Figueiredo, J.C.P., Campilho, R.D.S.G., Marques, E.A.S., Machado, J.J.M., da Silva, L.F.M. (2018). Adhesive thickness influence on the shear fracture toughness measurements of adhesive joints, Int. J. Adhes. Adhes.,

DOI: $10.1016 /$ j.jiadhadh.2018.02.015. 
[11] Aydin A; Temiz, S, M.D.O. (2005). The effect of adherend thickness on the failure of adhesively-bonded single-lap joints, J. Adhes. Sci. Technol., 19(8), pp. 8, DOI: 10.1163/1568561054890499.

[12] Trimiño, L.F., Cronin, D.S. (2016). Evaluation of Numerical Methods to Model Structural Adhesive Response and Failure in Tension and Shear Loading, J. Dyn. Behav. Mater., 2(1), pp. 122-137, DOI: 10.1007/s40870-016-0045-7.

[13] Saraç, İ., Adin, H., Temiz, Ş. (2018). Experimental determination of the static and fatigue strength of the adhesive joints bonded by epoxy adhesive including different particles, Compos. Part B Eng., 155, pp. 92-103, DOI: 10.1016/J.COMPOSITESB.2018.08.006.

[14] Adams, R.D., Peppiatt, N.A. (1974). Stress analysis of adhesive-bonded lap joints, J. Strain Anal., 9(3), pp. 185-196, DOI: $10.1243 / 03093247$ V093185.

[15] Niranjan, V. (1970). Bonded joints, A Rev. Eng. 1970 UTIAS Rev., (28).

[16] Grant, L.D.R., Adams, R.D., da Silva, L.F.M. (2009). Experimental and numerical analysis of single-lap joints for the automotive industry, Int. J. Adhes. Adhes., 29(4), pp. 405-413, DOI: 10.1016/j.ijadhadh.2008.09.001.

[17] Araujo, H.A.M., Machado, J.J.M., Marques, E.A.S., da Silva, L.F.M. (2017). Dynamic behaviour of composite adhesive joints for the automotive industry, Compos. Struct., 171, pp. 549-561, DOI: 10.1016/j.compstruct.2017.03.071.

[18] Blackman, B.R.K., Kinloch, A.J., Rodriguez Sanchez, F.S., Teo, W.S., Williams, J.G. (2009). The fracture behaviour of structural adhesives under high rates of testing, Eng. Fract. Mech., 76(18), pp. 2868-2889, DOI: 10.1016/j.engfracmech.2009.07.013.

[19] Lißner, M., Alabort, E., Cui, H., Pellegrino, A., Petrinic, N. (2018). On the rate dependent behaviour of epoxy adhesive joints: Experimental characterisation and modelling of mode I failure, Compos. Struct., 189(September 2017), pp. 286303, DOI: 10.1016/j.compstruct.2018.01.019.

[20] Avendaño, R., Carbas, R.J.C., Marques, E.A.S., da Silva, L.F.M., Fernandes, A.A. (2016). Effect of temperature and strain rate on single lap joints with dissimilar lightweight adherends bonded with an acrylic adhesive, Compos. Struct., 152, pp. 34-44, DOI: 10.1016/j.compstruct.2016.05.034.

[21] Boutar, Y., Naïmi, S., Mezlini, S., Da Silva, L.F.M., Hamdaoui, M., Ben Sik Ali, M. (2016). Effect of adhesive thickness and surface roughness on the shear strength of aluminium one-component polyurethane adhesive single-lap joints for automotive applications, J. Adhes. Sci. Technol., 30(17), pp. 1913-1929, DOI: 10.1080/01694243.2016.1170588.

[22] Elices, M., Guinea, G.V., Gómez, J., Planas, J. (2002). The cohesive zone model: advantages, limitations and challenges, Eng. Fract. Mech., 69(2), pp. 137-163, DOI: 10.1016/S0013-7944(01)00083-2.

[23] Campilho, R.D.S.G., Banea, M.D., Neto, J.A.B.P., Da Silva, L.F.M. (2013). Modelling adhesive joints with cohesive zone models: Effect of the cohesive law shape of the adhesive layer, Int. J. Adhes. Adhes., 44, pp. 48-56, DOI: $10.1016 /$ j.ijadhadh.2013.02.006.

[24] May, M., Hesebeck, O., Marzi, S., Böhme, W., Lienhard, J., Kilchert, S., Brede, M., Hiermaier, S. (2015). Rate dependent behavior of crash-optimized adhesives - Experimental characterization, model development, and simulation, Eng. Fract. Mech., 133, pp. 112-137, DOI: 10.1016/j.engfracmech.2014.11.006.

[25] 3M. (y.y.). Scotch-Weld TM Epoxy Adhesives DP460 Off-White and DP460NS.

[26] ASTM D1002. (1999). Standard test method for Apparent Shear Strenght of Single-Lap-Joint Adhesively Bonded Metal Specimens by Tension Loading (Metal - to - Metal), , pp. 1-5, DOI: 10.1520/D3433-99.

[27] (1990). ASM Handbook Volume 2: Properties and Selection: Nonferrous Alloys and Special-Purpose Materials, ASM International.

[28] Ansys. (y.y.). ANSYS Engineering Analysis System User's Manual.

[29] El-Emam, H.M., Salim, H.A., Sallam, H.E.M. (2017). Composite Patch Configuration and Prestress Effect on SIFs for Inclined Cracks in Steel Plates, J. Struct. Eng. (United States), 143(5), pp. 1-12,

DOI: 10.1061/(ASCE)ST.1943-541X.0001727.

[30] Jousset, P., Rachik, M. (2014). Comparison and evaluation of two types of cohesive zone models for the finite element analysis of fracture propagation in industrial bonded structures, Eng. Fract. Mech., 132, pp. 48-69, DOI: $10.1016 /$ j.engfracmech.2014.10.018.

[31] Atta, M., Abd-Elhady, A.A., Abu-Sinna, A., Sallam, H.E.M. (2019). Prediction of failure stages for double lap joints using finite element analysis and artificial neural networks, Eng. Fail. Anal., 97(July 2018), pp. 242-257,

DOI: 10.1016/j.engfailanal.2019.01.042.

[32] da Silva, L.F.M., Rodrigues, T.N.S.S., Figueiredo, M.A. V., de Moura, M.F.S.F., Chousal, J.A.G. (2006). Effect of adhesive type and thickness on the lap shear strength, J. Adhes., 82(11), pp. 1091-115, DOI: $10.1080 / 00218460600948511$.

[33] Campilho, R.D.S.G., Moura, D.C., Banea, M.D., Da Silva, L.F.M. (2015). Adhesive thickness effects of a ductile adhesive by optical measurement techniques, Int. J. Adhes. Adhes., 57, pp. 125-132, 
DOI: 10.1016/j.ijadhadh.2014.12.004.

[34] Richard W. Hertzberg, Richard P. Vinci, J.L.H. (2012). Deformation and Fracture Mechanics of Engineering Materials.

[35] Goldberg, R.R.K. (1999). Strain rate-dependent deformation and strength modeling of a polymer matrix composite utilizing a micromechanics approach, (December), pp. 172.

[36] Zgoul, M., Crocombe, A.D. (2004). Numerical modelling of lap joints bonded with a rate-dependent adhesive, Int. J. Adhes. Adhes., 24(4), pp. 355-366, DOI: 10.1016/j.ijadhadh.2003.11.006.

[37] Paul, H., Ledford, N., Sauer, M., May, M., Okamura, M. (2018). Assessment of test methods for thick and thin layer adhesive joints under high rates of loading, Int. J. Adhes. Adhes., 83(March), pp. 123-129, DOI: 10.1016/j.ijadhadh.2018.02.025.

[38] Machado, J.J.M., Marques, E.A.S., Silva, M.R.G., da Silva, L.F.M. (2018). Numerical study of impact behaviour of mixed adhesive single lap joints for the automotive industry, Int. J. Adhes. Adhes., 84(February), pp. 92-100, DOI: $10.1016 /$ j.ijadhadh.2018.02.036.

[39] Hein, V.L., Erdogan, F. (1971). Stress singularities in a two-material wedge, Int. J. Fract. Mech., 7(3), pp. 317-330, DOI: $10.1007 / \mathrm{BF} 00184307$.

[40] Harvey, C.M., Wood, J.D., Wang, S. (2015). Brittle interfacial cracking between two dissimilar elastic layers: Part 1Analytical development, Compos. Struct., 134, pp. 1076-1086, DOI: 10.1016/j.compstruct.2015.06.080. 